\title{
The Crystallization of Amorphous Aluminum Oxide Thin Films
} Grown on $\mathrm{NiAl}(\mathbf{1 0 0})$

\author{
Hailang Qin, ${ }^{\star}$ Peter Sutter ${ }^{\S}$ and Guangwen Zhou ${ }^{\star \dagger}$ \\ ${ }^{\star}$ Department of Mechanical Engineering and Multidisciplinary Program in Materials Science and Engineering, State University \\ of New York, Binghamton, New York 13902 \\ ${ }^{\S}$ Center for Functional Nanomaterials, Brookhaven National Laboratory, Upton, New York 11973
}

\begin{abstract}
The crystallization of amorphous aluminum oxide thin films formed on $\mathrm{NiAl}(100)$ has been investigated using in-situ low energy electron microscopy, low energy electron diffraction, and scanning tunneling microscopy. It is found that both the annealing temperature and annealing time play crucial roles in the crystallization process. A critical temperature range of $450^{\circ} \mathrm{C}-500^{\circ} \mathrm{C}$ exists for the crystallization to occur within a reasonably short annealing time. The initially uniform oxide film first becomes roughened, followed by coalescing into amorphous-like oxide islands; further annealing results in the conversion of the amorphous oxide islands into crystalline oxide stripes. The density of the crystalline oxide stripes increases concomitantly with the decrease in the density of the amorphous oxide islands for annealing at a higher temperature or longer time.
\end{abstract}

\section{Introduction}

A LUMINUM oxide thin films have important applications in microelectronics, protective coatings, and catalysis. In particular, the formation of aluminum oxide on $\mathrm{NiAl}$ substrates has been studied extensively owing to its important applications in harsh environments ranging from high-temperature materials in propulsion systems and gas turbine engines to ambient-temperature reactions, such as surface catalysts and electronic metallization. ${ }^{1-14}$ The aluminum oxides on $\mathrm{NiAl}(100)$ were typically formed by directly oxidizing a clean $\mathrm{NiAl}(100)$ surface at a high temperature (typically around $727^{\circ} \mathrm{C}$ or above) or by exposing a clean $\mathrm{NiAl}(100)$ surface to oxygen gas at room temperature followed by annealing at a high temperature, both of which would result in fully- or partially crystallized oxides. ${ }^{9,10}$ Most of the studies focused on investigating the properties of the crystalline oxides due to their stable electronic and geometric structures, with only a few exceptions focusing on the study of amorphous aluminum oxides formed on $\mathrm{NiAl}(100)$ substrates. For instance, Gaßmann et al. ${ }^{15,16}$ investigated the oxide structure with electron energy loss spectroscopy after annealing the room-temperature-oxidized surface at $427^{\circ} \mathrm{C}$. An alteration of the local structure within the oxide film was suggested and the structure of oxide film was still found to be different from the crystallized oxide film formed after annealing at $927^{\circ} \mathrm{C}$. Using low-energy electron microscopy (LEEM), McCarty ${ }^{17}$ studied the crystallization of the amorphous oxide films formed by oxidation of $\mathrm{NiAl}(110)$ at $325^{\circ} \mathrm{C}$ and found that crystallized oxide domains and oxide-free regions

N. Jacobson-contributing editor

Manuscript No. 34464. Received January 29, 2014; approved May 8, 2014

${ }^{\dagger}$ Author to whom correspondence should be addressed. e-mail: gzhou@ binghamton.edu developed on the surface when the amorphous oxide was annealed at $695^{\circ} \mathrm{C}$ and above. In addition to the aforementioned studies on the amorphous aluminum oxide films formed from the oxidation of $\mathrm{NiAl}$ alloys, the crystallization of amorphous $\mathrm{Al}_{2} \mathrm{O}_{3}$ thin films formed on silicon by atomic layer deposition was studied using grazing-incidence X-ray diffraction, which indicates that decreasing oxide film thickness leads to a higher crystallization temperature. ${ }^{18}$ However, important information regarding the range of critical temperatures at which the amorphous alumina films starts to crystallize and the associated film morphological evolution within the temperature range is still not elucidated. Thus far, there are no detailed studies on the nucleation and growth of the crystalline aluminum oxide out of the amorphous alumina films. In general, there is a lack of study on how an amorphous oxide thin film transforms into a crystalline oxide, which is especially important in controlling both the morphologies and atomic structures of the oxide films, and thus their electrical and chemical properties.

In this article, the crystallization process of the amorphous aluminum oxide films formed on a clean $\mathrm{NiAl}(100)$ surface is studied in detail using a combination of in-situ LEEM, low energy electron diffraction (LEED), and scanning tunneling microscopy (STM). The oxide formed by room-temperature oxygen exposure was annealed to different temperatures for different time periods. The surface morphology evolution of the oxide films was characterized by both LEEM and STM, and the structure of the oxide films was characterized with LEED. A simple "time-temperature" map for the crystallization of $\mathrm{Al}_{2} \mathrm{O}_{3}$ thin films was obtained from the experimental measurements.

\section{Experimental Procedure}

The STM and LEED experiments were performed in the STM chamber and analysis chamber of an ultra-high vacuum (UHV) system from RHK Technology Inc (Troy, MI). The base pressures in the two chambers were about $7 \times 10^{-11}$ and $2 \times 10^{-10}$ Torr respectively. The single-crystal NiAl(100) substrate, purchased from Princeton Scientific Corp. (Princeton, NJ), has an orientation accuracy better than $0.1^{\circ}$ to the (100) crystallographic orientation. For each cycle, the oxidation started with a freshly cleaned surface, which was achieved by flashing the sample up to $1100^{\circ} \mathrm{C}-1200^{\circ} \mathrm{C}$ a few times. Surface cleanliness and order were checked by Auger electron spectroscopy, X-ray Photoelectron spectroscopy (XPS) and LEED. The oxidation was performed by exposing the clean surface to oxygen gas at a partial pressure of $1 \times 10^{-7}$ Torr at room temperature for $100 \mathrm{~s}$. The oxide film formed under this condition has a thickness of $\sim 3 \AA$, which may correspond to a monolayer of $\mathrm{Al}_{2-x} \mathrm{O}_{3}$, where $x \sim 0.24$, as determined from the XPS $\mathrm{Al} / \mathrm{O}$ peak intensity ratio. ${ }^{19}$ For the first set of experiments, the sample temperature was raised to $500^{\circ} \mathrm{C}, 600^{\circ} \mathrm{C}, 650^{\circ} \mathrm{C}$, and $750^{\circ} \mathrm{C}$, and the sample 
was annealed for $5 \mathrm{~min}$. The sample was annealed for $30 \mathrm{~min}$ at each temperature for the second set of experiments. For another two sets, the sample was annealed at $550^{\circ} \mathrm{C}$ for $2 \mathrm{~h}$ and $500^{\circ} \mathrm{C}$ for $4 \mathrm{~h}$ respectively. Both the LEED and STM measurements were performed after the sample cooled down to room temperature. The STM imaging was performed with an electrochemically etched W tip and the bias was applied on the sample.

The LEEM experiments were carried out in a separate UHV system with a base pressure of about $4 \times 10^{-10}$ Torr. All the LEEM images were obtained in bright field mode. The sample was cleaned with the same method as the one used for the STM and LEED measurement. The LEEM images were taken in-situ while exposing the clean surface to oxygen gas at a partial pressure of $2 \times 10^{-9}$ Torr at around $250^{\circ} \mathrm{C}$ for about $100 \mathrm{~s}$ and while annealing the sample at each specified temperature for a few minutes.

\section{Results and Discussions}

Figures 1(a)-(f) show a series of LEEM images taken from the clean surface, the surface after the $\mathrm{O}_{2}$ exposure at $\sim 250^{\circ} \mathrm{C}$, and the surface after annealing at around $500^{\circ} \mathrm{C}$, $550^{\circ} \mathrm{C}, 600^{\circ} \mathrm{C}$, and $800^{\circ} \mathrm{C}$, respectively, each for several minutes. As seen in Fig. 1(a), the clean surface shows a high density of slightly curved steps, and the step edges appear as sharp dark lines in the LEEM images. As seen in Fig. 1(b), upon exposure to $\mathrm{O}_{2}$ gas at a partial pressure of $2 \times 10^{-9}$ Torr at $\sim 250^{\circ} \mathrm{C}$, the overall features of the NiAl surface (i.e., the terrace width, step density and shape) are still visible and remain relatively unchanged, but the sharp contrast from the step edges became blurry. The entire surface shows a granular morphology, but the resolution in the LEEM images does not allow concluding that the oxide film is amorphous (the nature of the amorphous oxide film is inferred by LEED as shown later). Our previous XPS studies showed that the oxide film formed on $\mathrm{NiAl}(100)$ under the similar oxidation conditions is an aluminum oxide and the STM imaging showed that the oxide film has a relatively uniform thickness on the average across the entire surface as inferred by unchanged step height ( 3 A) across the different surface terraces before and after the oxidation. ${ }^{19}$ However, it is worth mentioning that the oxide film shows local variations in surface height due to the granular morphology at the nanoscale, i.e., the film thickness varies locally. The oxidized surface was then annealed at different temperatures and the surface morphological evolution was monitored by in-situ LEEM imaging during the annealing process. No noticeable changes in the surface morphology were observed until the annealing temperature reached $500^{\circ} \mathrm{C}$. Figure $1(\mathrm{c})$ is an insitu LEEM image from the surface after being annealed at $500^{\circ} \mathrm{C}$ for a few min, which shows that the dark line contrast from the step edges completely disappeared and the initially relatively uniform oxide film developed into coarsened grains (as shown later by LEED and STM, these coarsened grains are still amorphous, crystallized oxide grains show a much regular stripe morphology). Figure 1(d) reveals coarsening of the grains, which became more prominent after annealing at $550^{\circ} \mathrm{C}$. Figure $1(\mathrm{e})$ shows that some stripe-like structures started to appear at $600^{\circ} \mathrm{C}$; however, the details are not accessible at this point, because the size of these structures was too small to be resolved by LEEM imaging. Upon further annealing at higher temperatures, more stripes were formed. An example of the LEEM image of the surface after annealing at about $800^{\circ} \mathrm{C}$ is shown in Fig. 1(f), which reveals a high density of oxide stripes are uniformly distributed across the entire surface.

The in-situ LEEM observations described above demonstrate that the initially relatively uniform oxide film tends to form coarsened grains at the annealing temperature of around $500^{\circ} \mathrm{C}$ and that the crystallized oxide films have a stripe-like morphology. To gain a better understanding of
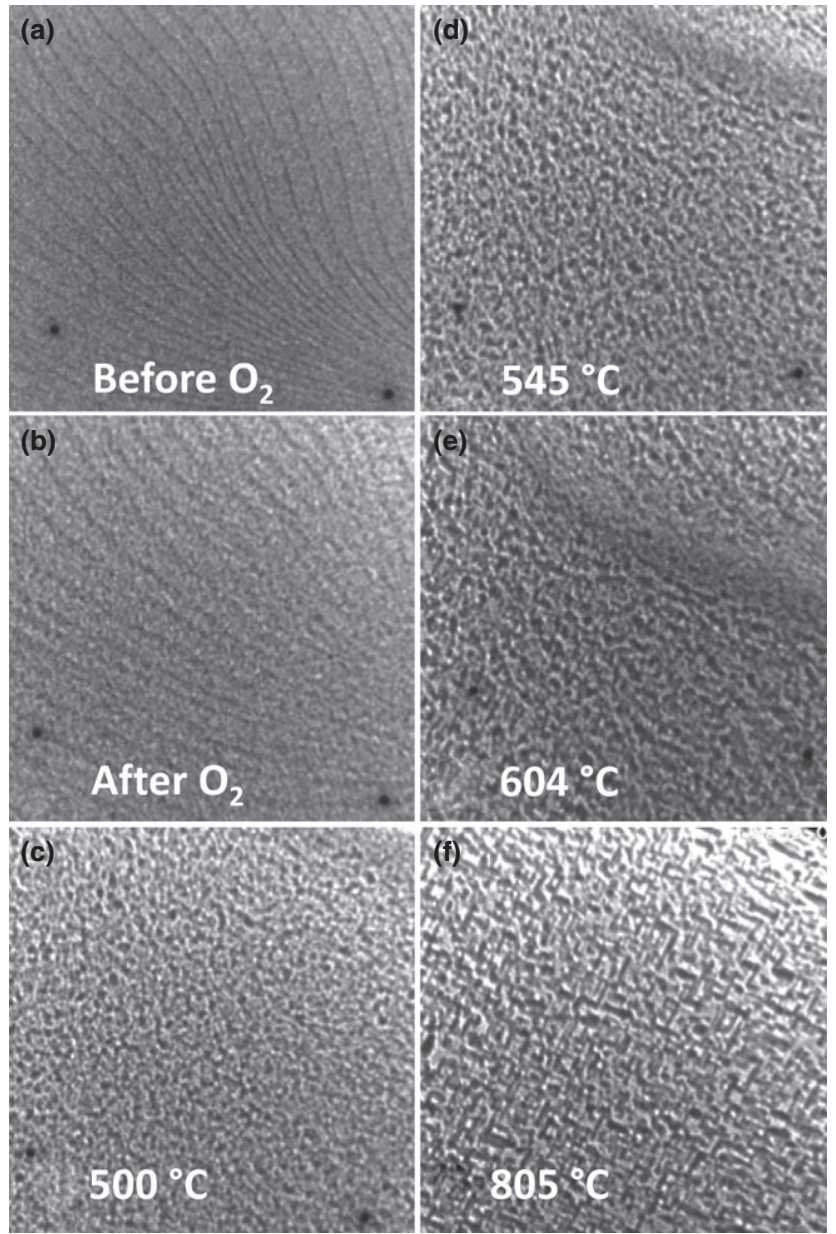

Fig. 1. Low-energy electron microscopy images (size: $(7.5 \mu \mathrm{m} \times 7.5 \mu \mathrm{m})$ of $\mathrm{NiAl}(100)$ : (a) before, (b) after $\mathrm{O}_{2}$ exposure, (c) after annealing at $500^{\circ} \mathrm{C}$, (d) $550^{\circ} \mathrm{C}$, (e) $600^{\circ} \mathrm{C}$, and (f) $800^{\circ} \mathrm{C}$ for a few min respectively. The drift is noticeable in the images. The two darks spots are the damages on the channel plate.

the crystallization process, LEED and STM studies were performed to acquire more details on the morphology and structure of the oxide films during the amorphous-crystalline transition upon annealing. Figures 2(a) and (b) show the LEED patterns of the clean $\mathrm{NiAl}(100)$ surface and the surface after exposure to oxygen gas with a pressure of $p \mathrm{O}_{2}=1 \times 10^{-7}$ Torr at room temperature for $100 \mathrm{~s}$. The clean-surface LEED patterns show that the clean surface had a $c(3 \sqrt{2} \times \sqrt{2}, \sqrt{2} \times 3 \sqrt{2}) R 45^{\circ}$ reconstruction $^{20,21}$ and it then changed to the $(1 \times 1)$ structure of the $\mathrm{NiAl}(100)$ substrate with significantly reduced intensity of the diffraction spots after the oxygen exposure. This indicates that the $c$ $(3 \sqrt{2} \times \sqrt{2}, \sqrt{2} \times 3 \sqrt{2}) R 45^{\circ}$ surface reconstruction of the $\mathrm{NiAl}(100)$ substrate was destroyed after the oxygen exposure and the surface was fully (or almost fully) covered by an amorphous oxide film. One can note that the LEED pattern of the clean $\mathrm{NiAl}(100)$ surface shows quite high background intensity. It may be caused by the presence of randomly distributed surface defects that varies with annealing condition, as discussed by Blum et al. ${ }^{9}$ The schematic of the LEED pattern showing the $(1 \times 1)$ substrate, the $c$ $(3 \sqrt{2} \times \sqrt{2}, \sqrt{2} \times 3 \sqrt{2}) R 45^{\circ}$ surface reconstruction on the clean surface, and the $(2 \times 1,1 \times 2)$ oxide superstructure is shown in Fig. 2(c).

Scanning tunneling microscopy images and the corresponding LEED patterns for the first set of the annealing experiment (i.e., annealing for $5 \mathrm{~min}$ ) are shown in Figs. 3(a)-(d). As can be seen in the inset LEED pattern in Fig. 3(a), the substrate spots are still visible, but their intensi- 

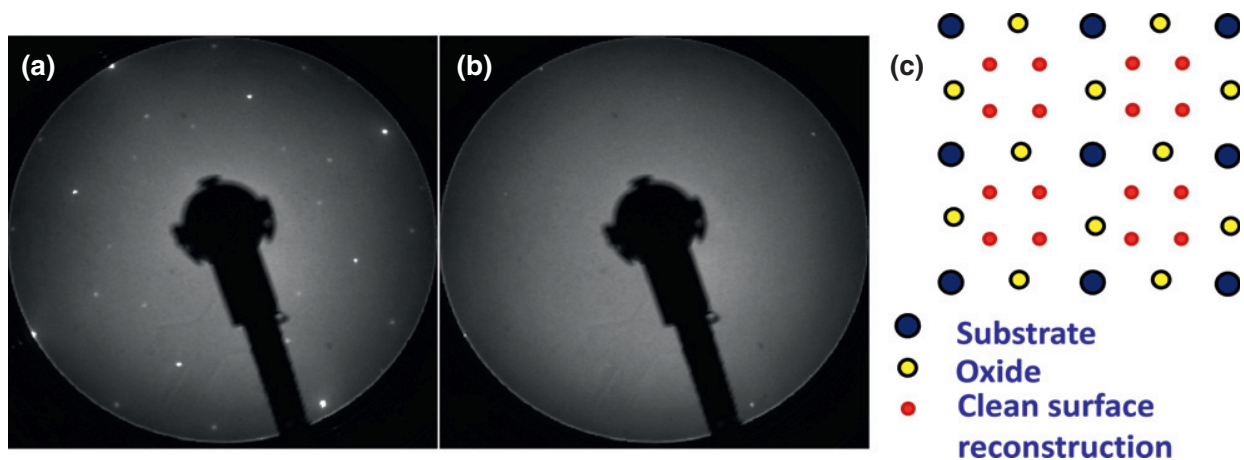

Fig. 2. Low energy electron diffraction (LEED) patterns of (a) the clean $\mathrm{NiAl}(100)$ surface, and (b) the $\mathrm{NiAl}(100)$ surface after exposure to oxygen of $1 \times 10^{-7}$ Torr at room temperature for $100 \mathrm{~s}$. Primary electron energy: $E_{\mathrm{P}}=121 \mathrm{eV}$. (c) Schematic of the LEED pattern showing the $(1 \times 1)$ substrate, the $c(3 \sqrt{2} \times \sqrt{2}, \sqrt{2} \times 3 \sqrt{2}) R 45^{\circ}$ reconstruction on the clean surface, and the $(2 \times 1,1 \times 2)$ oxide superstructure with streaks. The streaks are not shown in the schematic.

ties were further reduced after the oxide film was annealed at $500^{\circ} \mathrm{C}$ for $5 \mathrm{~min}$. As revealed by the LEEM images shown in Fig. 1 and the STM images in Fig. 3, one can note that the amorphous oxide films show an irregular granular feature while crystallized oxide films show a much regular stripe morphology. In addition to the LEED pattern, their distinct differences in the morphologies provides additional insight into the crystallization process. Although the STM images still show irregular granular amorphous feature, the surface started to form tiny islands (still amorphous oxide as revealed by the LEED pattern), and this causes the increased surface roughness ${ }^{22}$ compared to the initially uniform oxide film formed right after room temperature oxygen exposure. The observed surface morphological evolution is consistent with the in-situ LEEM observations shown in Fig. 1(c). The inset LEED pattern in Fig. 3(b) obtained from the oxide film annealed at $600^{\circ} \mathrm{C}$ for 5 min showed stronger substrate spots and very weak intensities around the $(2 \times 1,1 \times 2)$ locations associated with a crystalline oxide phase. ${ }^{16}$ The streaks in the LEED pattern of crystalline oxides formed on $\mathrm{NiAl}(100)$ are commonly observed by others and are usually attributed to the loss of ordering in the oxide film in the corresponding
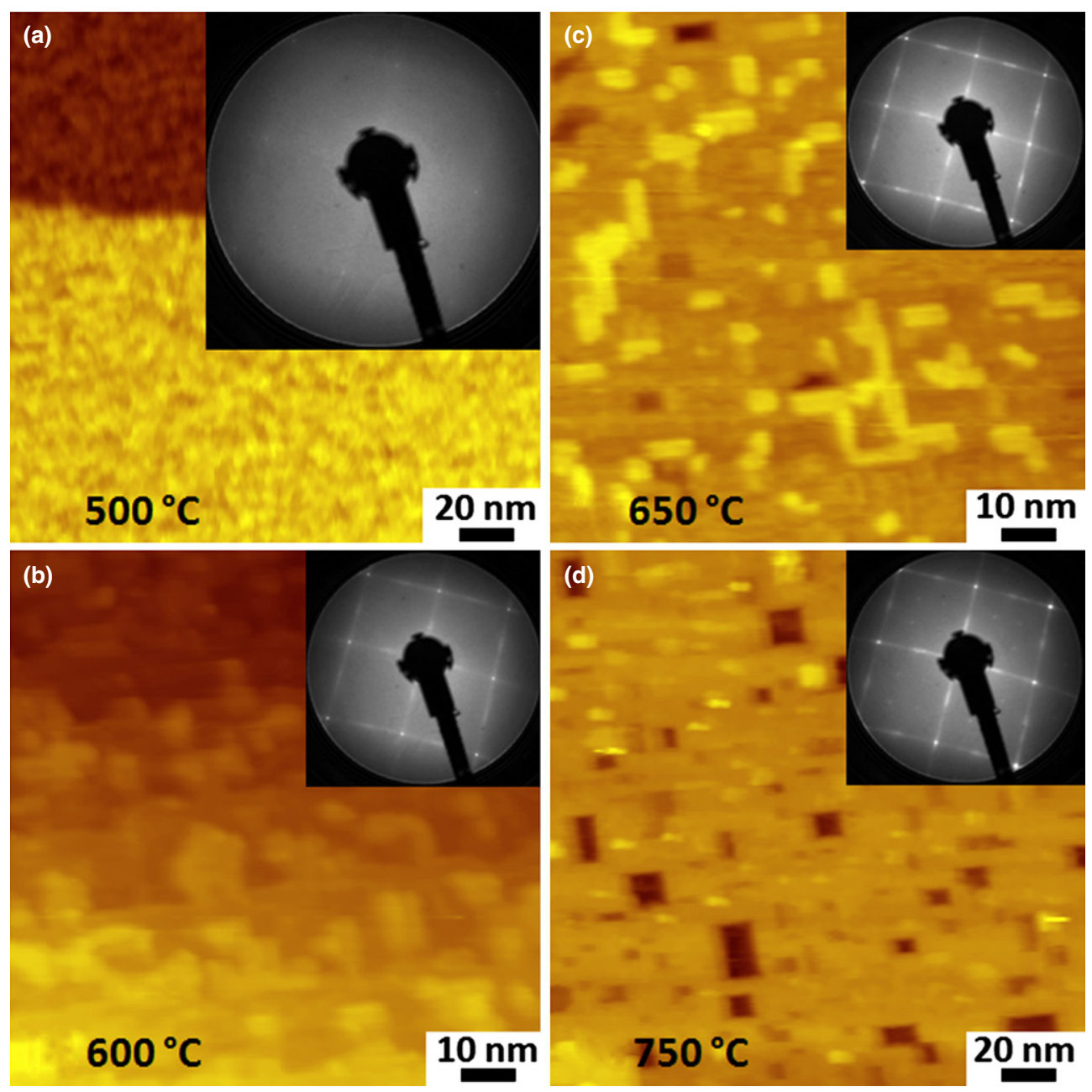

Fig. 3. Scanning tunneling microscopy images $\left(V_{\text {sample }}=-1 \mathrm{~V}, I_{\mathrm{t}}=1 \mathrm{n} A\right.$.) after annealing for $5 \mathrm{~min}$ at (a) $500^{\circ} \mathrm{C}$, (b) $600^{\circ} \mathrm{C},(\mathrm{c}) 650^{\circ} \mathrm{C}$, and $(\mathrm{d})$ $750^{\circ} \mathrm{C}$ respectively. The insets are the corresponding LEED patterns taken at a primary electron energy of $E_{\mathrm{P}}=131 \mathrm{eV}$ for (a) $-(\mathrm{c})$ and $113 \mathrm{eV}$ for (d). 
surface direction. ${ }^{16,23}$ The STM image shows that the annealed surface has now developed a significant amount of oxide islands. These oxide islands, however, did not show any long-range order, as evidenced by the lack of strong intensity of diffraction associated with the crystalline oxide phase. Figure 4(a) is a zoom-in STM image from these areas shown in Fig. 3(b) and it reveals that a small amount of crystalline thin oxide stripes had already formed, which likely gave rise to the weak intensity at the $(2 \times 1,2 \times 1)$ locations as shown in the inset LEED pattern in Fig. 3(b). With further (added on) annealing at $650^{\circ} \mathrm{C}$ for $5 \mathrm{~min}$, pronounced intensities appear at the $(2 \times 1,2 \times 1)$ locations as shown in the inset LEED pattern in Fig. 3(c), suggesting the formation of a non-negligible amount of crystalline oxides. This is also supported by the STM image in Fig. 3(c) and its enlarged view in Fig. 4(b), which show that more oxide stripes were
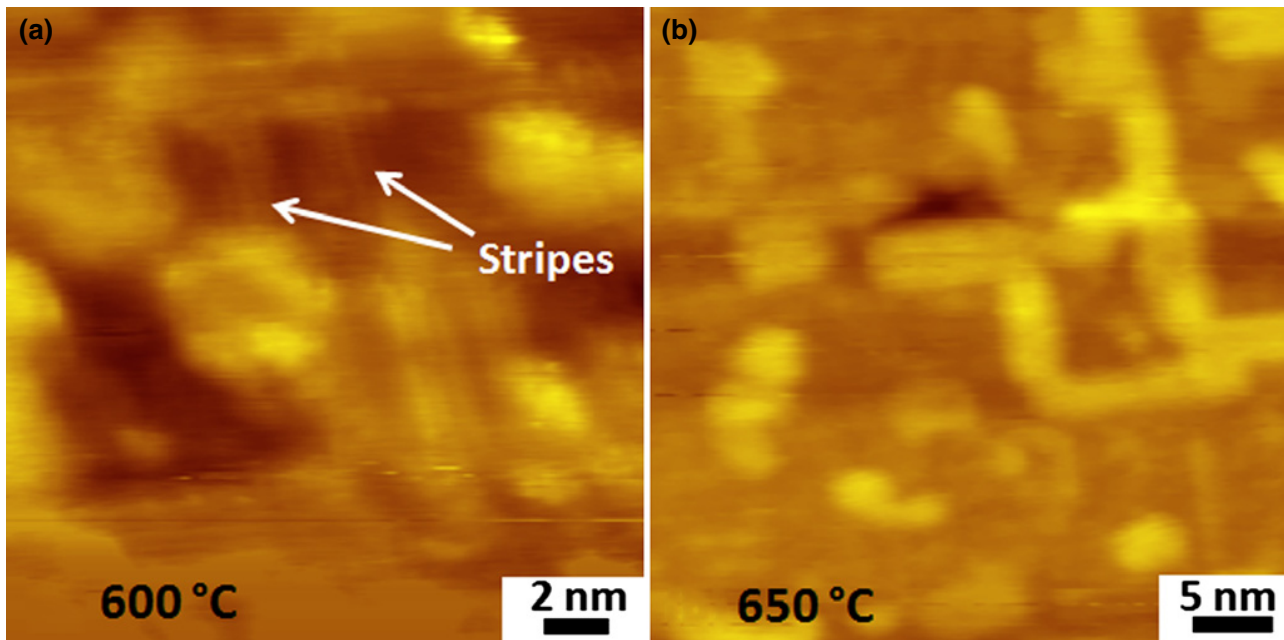

Fig. 4. Scanning tunneling microscopy images $\left(V_{\text {sample }}=-1 V, I_{\mathrm{t}}=1 \mathrm{n} A\right)$ of the oxide surface after annealing at (a) $600^{\circ} \mathrm{C}$ and $(\mathrm{b}) 650^{\circ} \mathrm{C}$ for 5 min respectively.
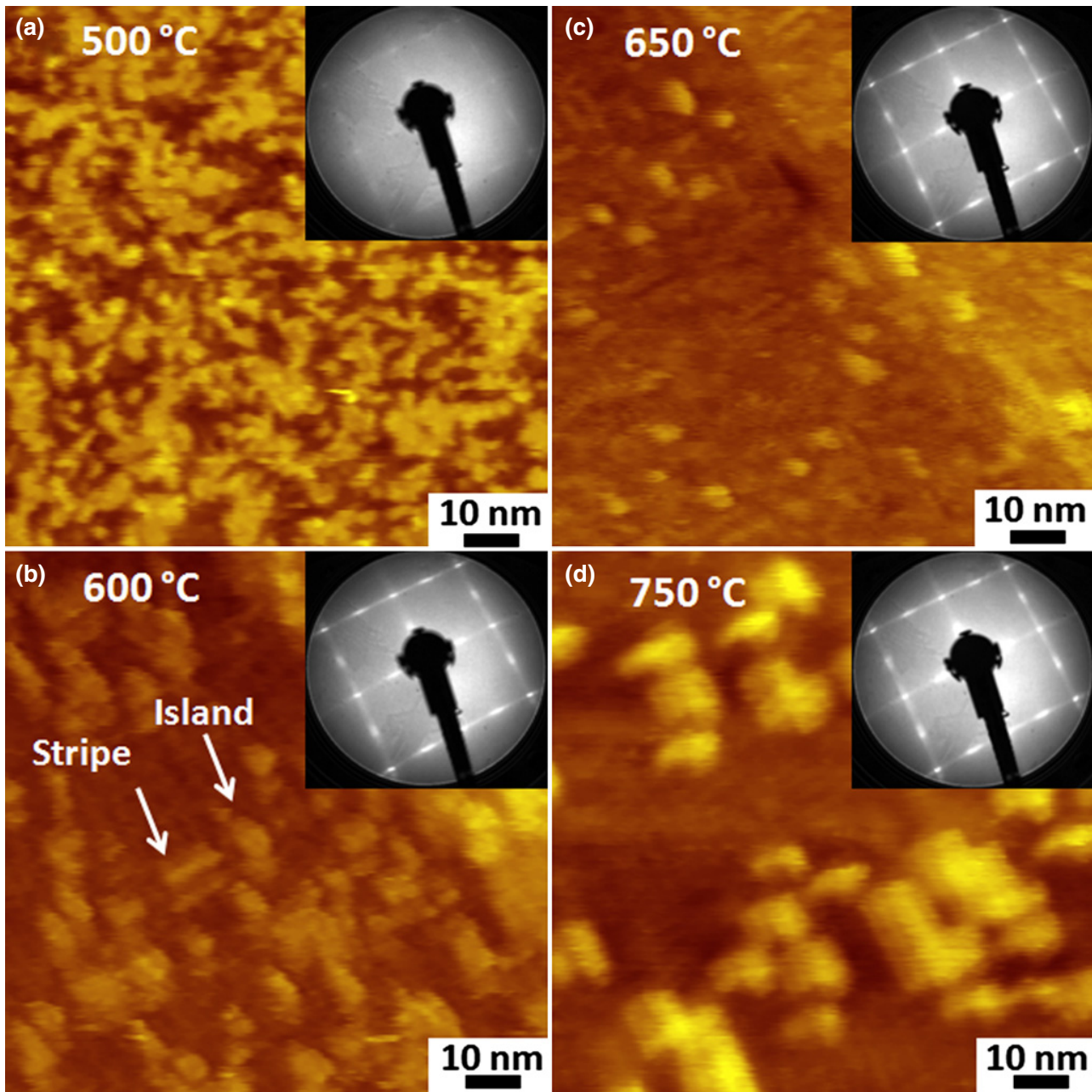

Fig. 5. Scanning tunneling microscopy images $\left(V_{\text {sample }}=-1 \mathrm{~V}, I_{\mathrm{t}}=1 \mathrm{n} A\right.$, area: $100 \mathrm{~nm} \times 100 \mathrm{~nm}$.) after annealing at (a) $500^{\circ} \mathrm{C}$, (b) $600^{\circ} \mathrm{C}$, (c) $650^{\circ} \mathrm{C}$, and (d) $750^{\circ} \mathrm{C}$ for $30 \mathrm{~min}$ respectively. The insets are the corresponding low energy electron diffraction patterns taken at a primary electron energy of $E_{\mathrm{P}}=131 \mathrm{eV}$. 
developed on the surface. After annealing at $750^{\circ} \mathrm{C}$ for $5 \mathrm{~min}$, the $c(3 \sqrt{2} \times \sqrt{2}, \sqrt{2} \times 3 \sqrt{2}) R 45^{\circ}$ spots associated with the clean $\mathrm{NiAl}(100)$ substrate re-appeared at low primary electron energies, e.g., $113 \mathrm{eV}$, which indicates that some nonoxidized areas appeared. One likely cause for the reappearance of the diffraction spots associated with the nonoxidized surface is that the initially uniform amorphous alumina film was broken into amorphous islands, which then transformed to crystalline alumina stripes, resulting in exposed oxide-free $\mathrm{NiAl}$ areas having the $\mathrm{c}$ $(3 \sqrt{2} \times \sqrt{2}, \sqrt{2} \times 3 \sqrt{2}) R 45^{\circ}$ reconstruction. This is also supported by the formation of surface depressions (which can be as deep as $0.6-0.8 \mathrm{~nm}$ ), as observed from the annealed surface [Figs. 3(c) and (d)]. However, we cannot exclude the possibility that the $c(3 \sqrt{2} \times \sqrt{2}, \sqrt{2} \times 3 \sqrt{2}) R 45^{\circ}$ reconstruction may reform at the alloy/oxide interface during annealing owning to the supply of $\mathrm{Al}$ atoms from the bulk to the alloy/ oxide interface that was depleted in $\mathrm{Al}$ by the oxide growth at room temperature.

It is shown in the preceding discussions that the amorphous aluminum oxide films started to crystallize at an annealing temperature of $\sim 500^{\circ} \mathrm{C}$ and the amorphous-to-crystalline transformation occurred via an island formation process by breaking up the initially uniform amorphous oxide film. On the other hand, the annealing time could also be an important factor in the crystallization. To explore the effect of annealing time, a similar set of experiment was carried out with an annealing time of $30 \mathrm{~min}$ at each temperature. The STM images and the corresponding LEED patterns are presented in Figs. 5(a)-(d). The surface after annealing at $500^{\circ} \mathrm{C}$ for $30 \mathrm{~min}$ was still dominated by the amorphous-like oxide islands, as evidenced by both LEED and STM. In addition, the STM image shows that the surface roughness increased further compared to the one after annealing for $5 \mathrm{~min}$ at the same temperature. The longer annealing time led to the coarsening of the amorphous oxide islands. After annealing at $600^{\circ} \mathrm{C}$ for $30 \mathrm{~min}$, the LEED pattern shows a clear $(2 \times 1,2 \times 1)$ superstructure, indicating the formation of crystalline oxide stripes. From the STM image in Fig. 5(b), it can be seen that both the amorphous oxide islands (which have less well-defined shapes) and the crystalline oxide stripes co-exist on the annealed surface. Comparing Figs. 3(b) and $5(\mathrm{~b})$, we find that the density of the amorphous oxide islands decreases with increasing the annealing time. Further annealing at $650^{\circ} \mathrm{C}$ for $30 \mathrm{~min}$ significantly reduced the density and sizes of the amorphous oxide islands. Meanwhile, the density of crystalline oxide stripes increased appreciably, with the majority of the surface being covered by thin stripes. After annealing at $750^{\circ} \mathrm{C}$, the amorphous oxide islands almost disappeared and about $40 \%$ of the surface was covered by the oxide stripes, some of which are very thin ones. The correlated size and density evolution between the amorphous oxide islands and the crystalline oxide stripes indicates that the crystallization occurred via progressive consumption of the parent amorphous oxide.

To better illustrate the surface roughness and island size changes during the crystallization process, typical line profiles and the root-mean-square (standard deviations) roughness of the images from the oxide films before annealing, annealed at $500^{\circ} \mathrm{C}$ for $5 \mathrm{~min}, 30 \mathrm{~min}$, and $4 \mathrm{~h}$ are plotted in Figs. 6(a) and (b) respectively. It can be seen that the root-mean-square (RMS) roughness did not change significantly after annealing at $500^{\circ} \mathrm{C}$ for $5 \mathrm{~min}$, but increased to $0.7 \AA$ after annealing for $30 \mathrm{~min}$ and became $0.9 \AA$ after annealing for $4 \mathrm{~h}$ (not added-on). Furthermore, the island lateral size increased accordingly with the annealing time.

From the set of results on the samples annealed for $5 \mathrm{~min}$ for each specified temperature, it is noted that the temperature plays a crucial role in driving the amorphous oxide to crystallize. For instance, a clear crystallization only started after annealing at $650^{\circ} \mathrm{C}$, not much occurred at $500^{\circ} \mathrm{C}$, or even at $600^{\circ} \mathrm{C}$. However, with increasing the annealing time to $30 \mathrm{~min}$ for each temperature, clear crystallization started to develop at even $600^{\circ} \mathrm{C}$. In fact, the amorphous-to-crystalline transformation could start at even a lower temperature. Figs. 7(a) and (b) show the LEED patterns obtained from the oxide films annealed at $550^{\circ} \mathrm{C}$ for $2 \mathrm{~h}$ and $500^{\circ} \mathrm{C}$ for $4 \mathrm{~h}$ respectively. Both of these LEED patterns indicate that the $(2 \times 1,2 \times 1)$ oxide superstructure had already formed after the relatively long-time annealing. However, at $450^{\circ} \mathrm{C}$, no clear crystallization occurred after annealing for $4 \mathrm{~h}$, or even for $10 \mathrm{~h}$, as shown in the LEED patterns in Figs. 7(c) and (d). This implies that the temperature range of $450^{\circ} \mathrm{C}-500^{\circ} \mathrm{C}$ is the critical temperature range for the crystallization process to occur within a reasonably short annealing time. The findings on the crystallization condition are summarized in the temperature-time-transformation diagram in Fig. 8, which shows that both the annealing temperature and annealing time play critical roles in the crystallization of the thin aluminum oxide films. For some of the annealing temperatures, shorter annealing times were not tested, thus the crystallization may start earlier as shown in the figure.

Figures 9(a)-(d) show schematically the crystallization process. Upon annealing at high temperature, the initially uniform amorphous oxide film starts to become roughened. With further annealing at higher temperature or longer time above the critical temperature, amorphous-like oxide islands start to form by coalescence of the amorphous granular oxide film and correspondingly resulting in exposed $\mathrm{NiAl}$ surface areas or thinner oxide areas. Further annealing leads to the conversion of the amorphous oxide islands to crystalline oxide stripes.
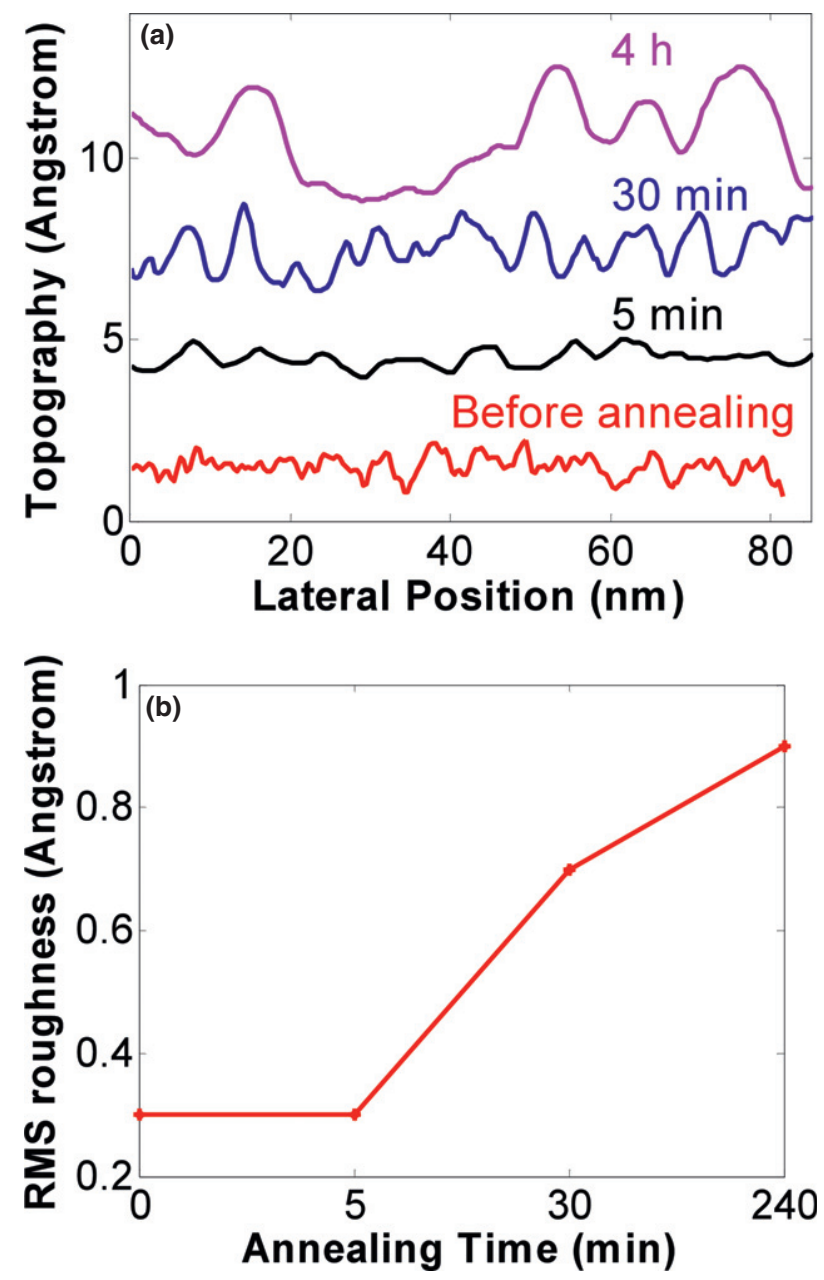

Fig. 6. (a) Line profiles and (b) RMS roughness of the surface before annealing, and annealed at $500^{\circ} \mathrm{C}$ for $5 \mathrm{~min}, 30 \mathrm{~min}$, and $4 \mathrm{~h}$ (240 $\mathrm{min})$. 
Our previous XPS measurements indicate that the aluminum oxide film formed by $1 \mathrm{~L}$ of oxygen exposure at room temperature has a thickness of $\sim 3 \AA$ with the stoichiometry of $\mathrm{Al}_{(2-x)} \mathrm{O}_{3}$, where $x \sim 0.24$, i.e., oxygen is present in excess with respect to Al. ${ }^{19}$ This is also consistent with other previous studies that showed the amorphous aluminum oxide films formed from the oxygen exposure at room temperature exhibit a deficiency of Al cations, where the oxide structure can be described by a close packing of oxygen anions with the $\mathrm{Al}$ cations distributed over the octahedral and/or tetrahedral interstices. ${ }^{24,25}$ Formation of more stoichiometric alumina during annealing requires the incorporation of additional $\mathrm{Al}$ atoms (assuming that oxygen desorption from the surface is negligible during the annealing). One can note from the STM images [i.e., Figs. 3(c) and (d)] that the oxide crystallization results in the formation of significant surface depressions (as deep as 0.6$0.8 \mathrm{~nm}$ ) with the lateral sizes up to $20 \mathrm{~nm}$, which can be a source of supplying $\mathrm{Al}$ atoms in addition to $\mathrm{Al}$ atoms from the bulk for the formation of more stoichiometric alumina. The formation of these large depressions is also good evidence demonstrating that the continuous amorphous aluminum oxide film breaks into discontinuous oxide islands upon annealing.

Exposure of a clean metal or alloy surface (e.g., Al, NiAl, and $\mathrm{FeAl}$ ) to oxygen at relatively low temperatures (below $300^{\circ} \mathrm{C}$ for $\mathrm{Al}$ and $500^{\circ} \mathrm{C}$ for $\mathrm{NiAl}$ ) typically results in the formation of an amorphous oxide film, whereas at higher temperatures the resulting structure of the corresponding oxide film is crystalline. The bulk Gibbs free energy of formation of the amorphous aluminum oxide is larger than that a crys- talline aluminum oxide (i.e., crystalline alumina is more stable than amorphous alumina. ${ }^{26}$ However, a thin amorphous aluminum oxide film can be more stable than the crystalline structure due to the surface and interface effect, as shown in a thermodynamic calculation by Jeurgens et al. ${ }^{26}$ With the

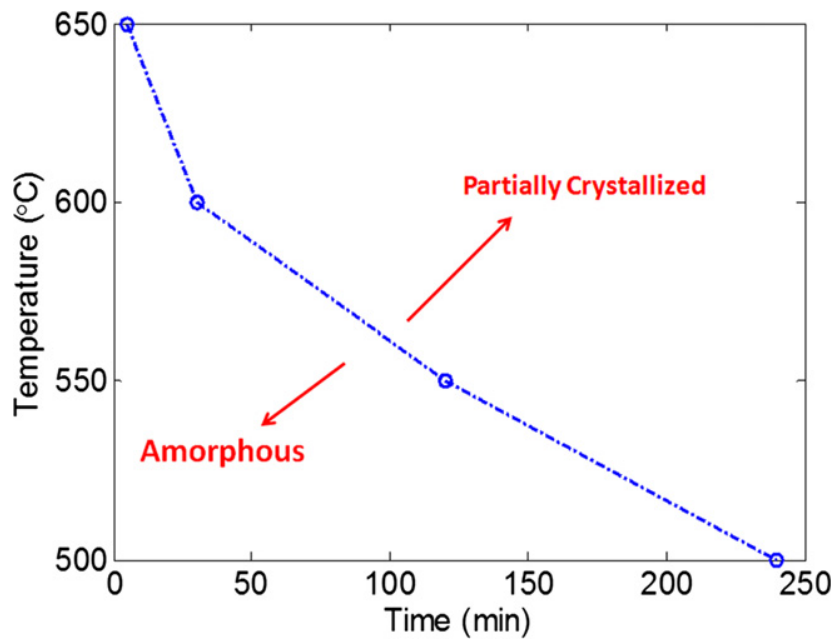

Fig. 8. Temperature-time-transformation diagram showing the crystallization of ultrathin amorphous aluminum oxide films formed on $\mathrm{NiAl}(100)$ by oxygen exposure at room temperature. The circles are the experimental results and the dotted lines are guides to the eye.
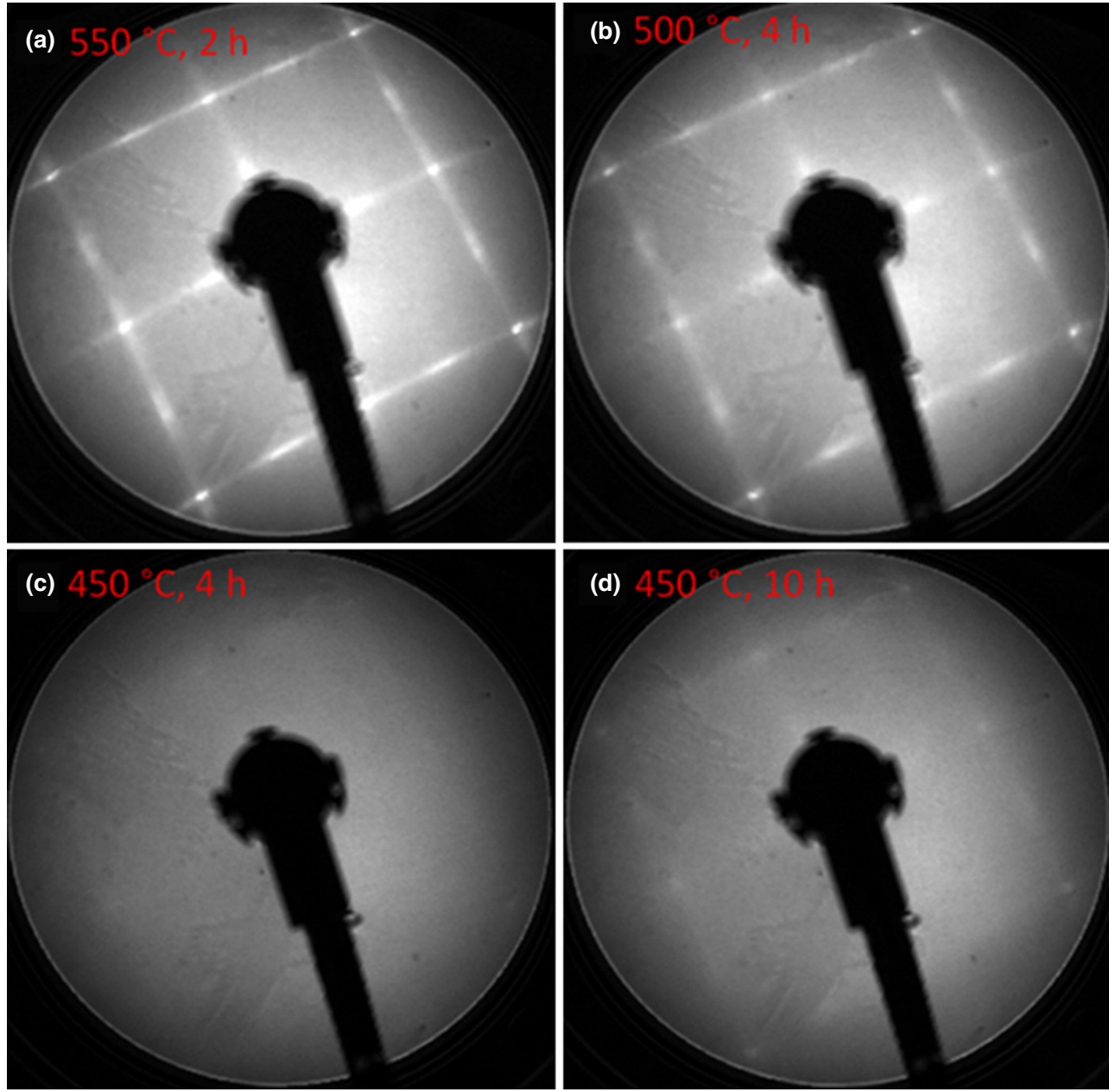

Fig. 7. Low energy electron diffraction patterns of the oxidized $\mathrm{NiAl}(100)$ surface after annealing at $550^{\circ} \mathrm{C}$ for $2 \mathrm{~h}$, at $500^{\circ} \mathrm{C}$ for $4 \mathrm{~h}$, at $450^{\circ} \mathrm{C}$ for $4 \mathrm{~h}$, and at $450^{\circ} \mathrm{C}$ for $10 \mathrm{~h}$. The electron primary energy was all $E_{\mathrm{p}}=131 \mathrm{eV}$. 


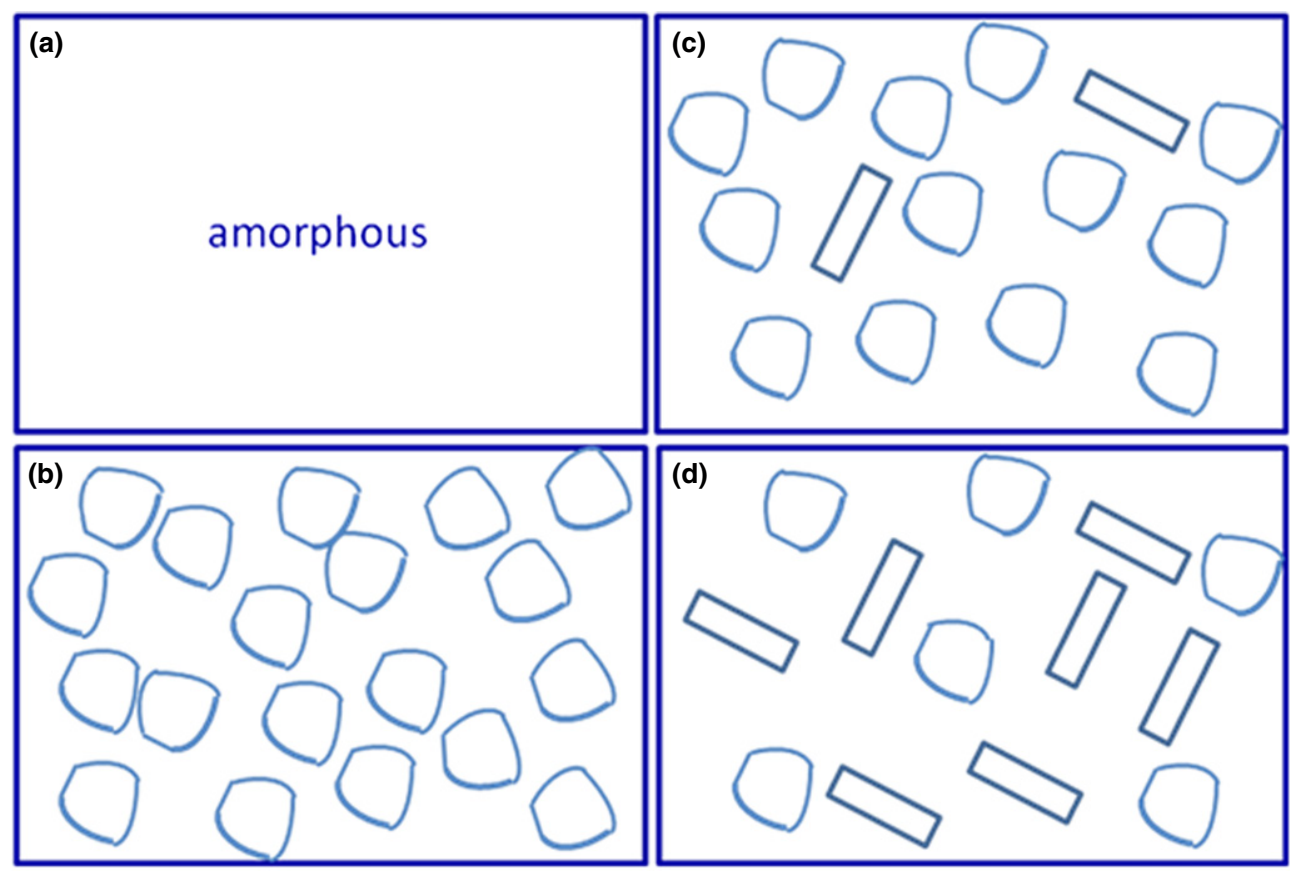

Fig. 9. Schematic showing the surface morphology changes in different stages of crystallization by annealing above the critical temperature, (a) as-formed continuous amorphous aluminum oxide film on $\mathrm{NiAl}(100)$; (b) formation of amorphous-like oxide islands by breaking up the continuous oxide film; (c) formation of crystalline oxide stripes by conversion of amorphous oxide islands; (d) the density of the crystalline oxide stripes increases by consuming amorphous oxide islands for continued annealing.

increase in temperature (i.e., annealing), a crystalline aluminum oxide film can become more stable than the amorphous oxide film because of the decrease in the bulk Gibbs free energy difference between the amorphous and crystalline oxides in addition to the change of the lattice mismatch at the oxide/alloy interface that may favor the formation of an epitaxial (i.e., crystalline) oxide film at elevated temperatures. The crystallization process requires massive mass transport for the amorphous $\rightarrow$ crystalline transformation including breaking up the initial continuous amorphous oxide film and re-arrangement of atoms at the oxide/alloy interface. Therefore, a critical annealing temperature (i.e., $500^{\circ} \mathrm{C}$ as determined from our observation) is required that allows for sufficient mobility of $\mathrm{Al}$ and $\mathrm{O}$ atoms for the structure ordering in the oxide film. Crystallization of Al-deficient oxide films formed at room temperature calls for the supply of $\mathrm{Al}$ atoms from the oxide-free surface regions (e.g., surface depressions as observed in Figs. 3 and 4) via surface diffusion. Bulk diffusion to the oxide/alloy interface is another source of supplying additional $\mathrm{Al}$ atoms for the formation of more stoichiometric crystalline aluminum oxide.

\section{Conclusion}

In conclusion, the morphological and structural transformation during the crystallization of the amorphous aluminum oxide thin grown on $\mathrm{NiAl}(100)$ surface was studied using the surface science tools of LEEM, STM, and LEED. We found that the thermally induced crystallization starts with roughening of the amorphous oxide thin film, which is followed by coalescing into amorphous-like oxide islands. Upon further annealing, the amorphous oxide islands undergo coarsening and then gradually transform into crystalline oxide stripes. With the continued crystallization, the density and size of the amorphous oxide islands decreases, with the correlated increase in the density and size of the crystalline oxide stripes. It is shown that both the annealing temperature and annealing time play important roles in the crystallization process and a critical annealing temperature of $450^{\circ} \mathrm{C}-500^{\circ} \mathrm{C}$ is necessary for the crystallization to occur within a few hours.

\section{Acknowledgments}

This work was supported by the U.S. Department of Energy, Office of Basic Energy Sciences, Division of Materials Sciences and Engineering under award no. DE-FG02-09ER46600. Research carried out in part at the Center for Functional Nanomaterials, Brookhaven National Laboratory, which is supported by the U.S. Department of Energy, Office of Basic Energy Sciences, under contract no. DE-AC02-98CH10886.

\section{References}

${ }^{1}$ R. Darolia, "NiAl Alloys for High-Temperature Structural Applications," JOM, 43 [3] 44-9 (1991).

${ }^{2}$ N. Frémy, V. Maurice, and P. Marcus, "X-ray Photoelectron Spectroscopy Study of Thin Oxide Layers Formed on (001)-Oriented $\beta$-NiAl Single-Crystal Surfaces," Surf. Interface Anal., 34 [1] 519-23 (2002).

${ }^{3}$ A. Stierle, V. Formoso, F. Comin, and R. Franchy, "Surface X-ray Diffraction Study on the Initial Oxidation of NiAl(100)," Surf. Sci., 467 [1-3] 85-97 (2000).

${ }^{4}$ W.-C. Lin, C.-C. Kuo, M.-F. Luo, K.-J. Song, and M.-T. Lin, "SelfAligned Co Nanoparticle Chains Supported by Single-Crystalline $\mathrm{Al}_{2} \mathrm{O}_{3} \mathrm{NiAl}$ (100) Template," Appl. Phys. Lett., 86 [4] 043105, 3 pp (2005).

${ }^{5}$ M. F. Luo, C. I. Chiang, H. W. Shiu, S. D. Sartale, and C. C. Kuo, "Patterning Co Nanoclusters on Thin-Film $\mathrm{Al}_{2} \mathrm{O}_{3} / \mathrm{NiAl}(100)$," Nanotechnology, 17 [2] 360-6 (2006).

${ }^{6}$ M. S. Zei, C. S. Lin, W. H. Wen, C. I. Chiang, and M. F. Luo, "Growth of $\mathrm{Al}_{2} \mathrm{O}_{3}$ Thin Films on NiAl(100) by Gas-Phase Oxidation and Electro-Oxidation," Surf. Sci., 600 [9] 1942-51 (2006).

${ }^{7}$ M. F. Luo, W. H. Wen, C. S. Lin, C. I. Chiang, S. D. Sartale, and M. S. $\mathrm{Zei}$, "Structures of $\mathrm{Co}$ and $\mathrm{Pt}$ Nanoclusters on a Thin Film of $\mathrm{Al}_{2} \mathrm{O}_{3} / \mathrm{NiAl}$ (100) from Reflection High-Energy Electron Diffraction and Scanning-Tunnelling Microscopy," Surf. Sci., 601 [10] 2139-46 (2007).

${ }^{8}$ C. T. Wang, C. W. Lin, C. L. Hsia, B. W. Chang, and M. F. Luo, "Under-Surface Observation of Thin-Film Alumina on NiAl(100) with Scanning Tunneling Microscopy," Thin Solid Films, 520 [11] 3952-9 (2012).

${ }^{9}$ R.-P. Blum, D. Ahlbehrendt, and H. Niehus, "Preparation-Dependent Surface Composition and Structure of NiAl(001): SPA-LEED and NICISS Study," Surf. Sci., 366 [1] 107-20 (1996).

${ }^{10}$ R.-P. Blum and H. Niehus, "Initial Growth of $\mathrm{Al}_{2} \mathrm{O}_{3}$ on $\mathrm{NiAl}(001), "$ Appl. Phys. A, 66 [1] S529-33 (1998).

${ }^{11}$ J. P. Pierce and K. F. McCarty, "Self-Assembly and Dynamics of Oxide Nanorods on NiAl(110)," Phys. Rev. B, 71 [12] 125428, 11 pp (2005).

${ }^{12}$ C. W. Lin, C. T. Wang, and M. F. Luo, "Fabrication of Nanoscale Alumina on $\mathrm{NiAl}(100)$ with a Scanning Tunneling Microscope," Appl. Surf. Sci., 264 [0] 280-5 (2013).

${ }^{13}$ J. P. Pierce, N. C. Bartelt, R. Stumpf, and K. F. McCarty, "Stability of Ultrathin Alumina Layers on NiAl(110)," Phys. Rev. B, 77 [19] 195438, 7 pp (2008).

${ }^{14}$ P.-J. Hsu, C.-B. Wu, H.-Y. Yen, S.-S. Wong, W.-C. Lin, and M.-T. Lin, "Electronically Patterning Through One-Dimensional Nanostripes with High 
Density of States on Single-Crystalline $\mathrm{Al}_{2} \mathrm{O}_{3}$ Domain," Appl. Phys. Lett., 93 [14] 143104, 3 pp (2008).

${ }^{15} \mathrm{P}$. Gaßmann, R. Franchy, and H. Ibach, "Preparation of a Well Ordered Aluminum Oxide Layer on $\mathrm{NiAl}(001), " J$. Electron Spectrosc. Relat. Phenom., 64-65 [0] 315-20 (1993).

${ }^{16} \mathrm{P}$. Gassmann, R. Franchy, and H. Ibach, "Investigations on Phase Transitions Within Thin $\mathrm{Al}_{2} \mathrm{O}_{3}$ Layers on $\mathrm{NiAl}(001)$ - HREELS on Aluminum Oxide Films," Surf. Sci., 319 [1-2] 95-109 (1994).

${ }^{17}$ K. F. McCarty, "Imaging the Crystallization and Growth of Oxide Domains on the NiAl(100) Surface," Surf. Sci., 474 [1-3] L165-72 (2001).

${ }^{18}$ S. Jakschik, U. Schroeder, T. Hecht, M. Gutsche, H. Seidl, and J. W. Bartha, "Crystallization Behavior of Thin ALD- $\mathrm{Al}_{2} \mathrm{O}_{3}$ Films," Thin Solid Films, 425, 216-20 (2003).

${ }^{19}$ N. Cai, H. Qin, X. Tong, and G. Zhou, "Growth of Ultrathin Amorphous Alumina Films During the Oxidation of NiAl(100)," Surf. Sci., 618, 20-6 (2013).

${ }^{20}$ N. Frémy, V. Maurice, and P. Marcus, "Initial Stages of Growth of Alumina on NiAl(001) at 1025 K," J. Am. Ceram. Soc., 86 [4] 669-75 (2003).
${ }^{21}$ V. Maurice, N. Frémy, and P. Marcus, "Hydroxylation-Induced Modifications of the $\mathrm{Al}_{2} \mathrm{O}_{3} / \mathrm{NiAl}(001)$ Surface at Low Water Vapour Pressure," Surf. Sci., 581 [1] 88-104 (2005)

${ }^{22}$ H. Qin and G. Zhou, "The Formation of Double-Row Oxide Stripes During the Initial Oxidation of $\mathrm{NiAl}(100), " J$. Appl. Phys., 114 [8] 083513, 5 pp (2013).

${ }^{23}$ R.-P. Blum, D. Ahlbehrendt, and H. Niehus, "Growth of $\mathrm{Al}_{2} \mathrm{O}_{3}$ Stripes in NiA(001),"Surf. Sci., 396 [13] 176-88 (1998).

${ }^{24}$ L. P. H. Jeurgens, W. G. Sloof, F. D. Tichelaar, and E. J. Mittemeijer, "Structure and Morphology of Aluminium-Oxide Films Formed by Thermal Oxidation of Aluminium," Thin Solid Films, 418 [2] 89-101 (2002).

${ }^{25}$ L. P. H. Jeurgens, W. G. Sloof, F. D. Tichelaar, and E. J. Mittemeijer, "Growth Kinetics and Mechanisms of Aluminum-Oxide Films Formed by Thermal Oxidation of Aluminum," J. Appl. Phys., 92 [3] 1649-56 (2002).

${ }^{26}$ L. P. H. Jeurgens, W. G. Sloof, F. D. Tichelaar, and E. J. Mittemeijer, "Thermodynamic Stability of Amorphous Oxide Films on Metals: Application to Aluminum Oxide Films on Aluminum Substrates," Phys. Rev. B, 62 4707-19 (2000). 